\title{
Magnetic Resonance Imaging of Uterine Cervix: A Pictorial Essay
}

\author{
Foram B. Gala ${ }^{1,2}$ Kunal B. Gala ${ }^{3}$ Bharat M. Gala ${ }^{1}$ \\ 1Department of Radiology, Lifescan Imaging Centre, Mumbai, \\ Maharashtra, India \\ 2Department of Radiology, Bai Jerbai Wadia Hospital for Children, \\ Mumbai, Maharashtra, India \\ ${ }^{3}$ Department of Radiology, Tata Memorial Hospital, Mumbai, \\ Maharashtra, India \\ Indian J Radiol Imaging 2021;31:454-467.
}

\begin{abstract}
Address for correspondence Foram B. Gala, MD, Department of Radiology, Lifescan Imaging Centre, Malad, Mumbai, Maharashtra, 400064, India (e-mail: drforamgala@gmail.com).
\end{abstract}

\begin{abstract}
Keywords

- cervical lesions

- cervical cancer

- MRI of cervix

Uterine cervix is the lower constricted part of uterus which is best evaluated by magnetic resonance imaging (MRI) due to its higher soft tissue and contrast resolution. The cervical cancer is a common gynecological cancer causing much morbidity and mortality especially in developing countries. Cervical carcinomas mainly occurs in reproductive age group with prognosis mainly depending on the extent of disease at the time of diagnosis, hence it is important to identify these cancerous lesions early and stage them accurately for optimal treatment. In this article, we will review the following: (1) the normal MRI anatomy of uterine cervix; (2) MRI protocol and techniques in evaluation of cervical lesions; (3) imaging of spectrum of various congenital abnormalities and pathologies affecting uterine cervix which ranges from congenital abnormalities to various benign lesions of cervix like nabothian cysts, tunnel cysts, cervicitis, cervical fibroid, and, lastly, endometriosis which usually coexists with adenomyosis; the malignant lesions include carcinoma cervix, adenoma malignum or direct extension from carcinoma endometrium or from carcinoma of vagina; (4) Accurately stage carcinoma of cervix using FIGO classification (2018); and (5) posttreatment evaluation of cervical cancers. MRI is the most reliable imaging modality in evaluation of various cervical lesions, identification of cervical tumors, staging of the cervical malignancy, and stratifying patients for surgery and radiation therapy. It also plays an important role in detection of local disease recurrence.
\end{abstract}

\section{Introduction}

Uterine cervix is the lower constricted part of uterus which is best evaluated by magnetic resonance imaging (MRI) due to its higher soft tissue and contrast resolution. In this article, we shall evaluate the normal anatomy of cervix; optimal MRI techniques; and role of various sequences, congenital anomalies of cervix, benign, and malignant lesions involving cervix.

published online August 4, 2021
DOI https://doi.org/

$10.1055 / \mathrm{s}-0041-1734377$ ISSN 0971-3026

\section{Anatomy}

The word "cervix" means neck in Latin, is the lower fibromuscular portion of the uterus, cylindrical or conical in shape. The cervix projects into the vagina through the upper part of its anterior wall and opens through external opening, that is, external os. The upper half of cervix, above the vagina, is called supravaginal portion which is attached to the surrounding tissues, whereas the lower free portion

(C) 2021. Indian Radiological Association.

This is an open access article published by Thieme under the terms of the Creative Commons Attribution-NonDerivative-NonCommercial-License, permitting copying and reproduction so long as the original work is given appropriate credit. Contents may not be used for commercial purposes, or adapted, remixed, transformed or built upon. (https://creativecommons.org/licenses/by-nc-nd/4.0/).

Thieme Medical and Scientific Publishers Private Ltd. A-12, Second Floor, Sector -2, NOIDA -201301, India 
of cervix called portio vaginalis is limited by anterior and posterior vaginal fornices. The portio is further divided into anterior and posterior lips of which anterior lip is shorter and projects lower than posterior lip. The internal os (isthmus) is located between the supravaginal portion of cervix and uterine corpus. The ectocervix is the portion of cervix lying external to external os and is visualized on per speculum examination. ${ }^{1}$ The endocervix is proximal to external os and endocervical canal extends from internal to external os connecting the uterine cavity with the vagina. Maximum width of endocervical canal is $8 \mathrm{~mm}$. The endocervix is lined with columnar epithelium as compared with ectocervix which has nonkeratinizing squamous epithelium. With age, the squamous cells cover the columnar cells of endocervical glands resulting in superior migration of the squamocolumnar junction. This transitional area is most prone to development of carcinoma.

The cervix measures approximately 3 to $4 \mathrm{~cm}$ in length, and $2.5 \mathrm{~cm}$ in diameter; however, its size and shape vary depending on the woman's age, parity, and hormonal status. Before the onset of menstruation, the cervix is about half to two-thirds of that of uterus. In adult females, cervix constitutes about one-third of uterus, while in postmenopausal females, its length is almost same as uterine corpus. ${ }^{1,2}$

\section{Vascular Supply}

Blood supply to cervix is by descending branches of uterine arteries which are branches of anterior division of internal iliac arteries. These arteries reach the lateral cervical walls along the upper margins of cardinal ligaments. The venous drainage is parallel to arterial supply with communication with cervical plexus and neck of urinary bladder. The lymphatic drainage is to external iliac, obturator, hypogastric, common iliac, sacral nodes, and nodes of the posterior wall of urinary bladder. ${ }^{3}$

\section{Magnetic Resonance Imaging Technique and Imaging Protocol}

Patient Preparation

The scan is performed with the patient fasting for at least 4 hours to reduce bowel peristalsis artifacts. Patient is asked to empty the bladder and bowel before examination to reduce blurring from motion artifacts and ghosting due to bowel peristalsis and bladder motion. ${ }^{4}$ Intramuscular or intravenous administration of the antiperistaltic agents appears to improve image quality and lesion visualization in oncological pelvic MRI ${ }^{5}$; however, it is not a routine practice at our center. Sterilized gel is used to distend the vagina for better evaluation of cervical lesions. MRI should be performed before biopsy or at least 10 days after biopsy to avoid false positive results due to local inflammation. ${ }^{6}$

\section{Magnetic Resonance Imaging Protocol}

A phase-array surface coil is used to increase signal-to-noise ratio (SNR). We use following sequences on 3T Philips Achieva MRI Scanner:

1. Axial T2-weighted (T2W) fat saturated with large field of vision (FOV).
2. Axial T1-weighted (T1W) with large FOV.

3. Thin sagittal T2W.

4. Thin coronal $\mathrm{T} 2 \mathrm{~W}$.

5. Thin axial T2W.

6. Axial T1 fat saturated (if needed to differentiate fat from hemorrhage).

7. Diffusion-weighted images (DWIs).

8. Susceptibility-weighted images (SWIs; if required).

We first obtain T2 fat-saturated and T1W Turbo Spin Echo sequence in the true axial plane of the pelvis with large FOV to have global view of pelvis ( - Fig. 1). High-resolution, small FOV, 3- to 4-mm thick with zero-gap sections of T2Weighted sequences are obtained in the sagittal, oblique axial, and oblique coronal planes which are perpendicular and parallel to cervix (-Fig. 2). Sagittal T2W sequence is useful in assessing the location of lesion in cervix (anterior or posterior), its relation with uterine body, vagina, as well as with rectum and urinary bladder. Involvement of internal os and distance of tumor/lesion from internal os is also best seen on this plane.

Oblique axial T2W sequence is useful in assessment of parametrial and lateral pelvic invasion and bowel, bladder, and ureteric involvement with proximal hydroureter. Pelvic lymph nodes are well seen on true axial and coronal T2W images, as well as on DWIs; however, they are best visualized on T2 fat-saturated axial images with large FOV.

Oblique coronal plane assesses the invasion of parametrium well. $^{7}$

T1W images provide information on pelvic anatomy, help in evaluation of lymph nodes, and bone marrow. Hemorrhage in lesion appears hyperintense on T1W images and T1 fat-saturated images are helpful to differentiate it from fat.

We also perform DWI and SWI routinely in all the cases. DWI is extremely helpful in assessment of cellularity of the tumors. Cervical carcinomas show restricted diffusion, that is, hyperintense signal on DWI and hypointense signal on ADC maps, thus facilitating the exact extent of the tumor.

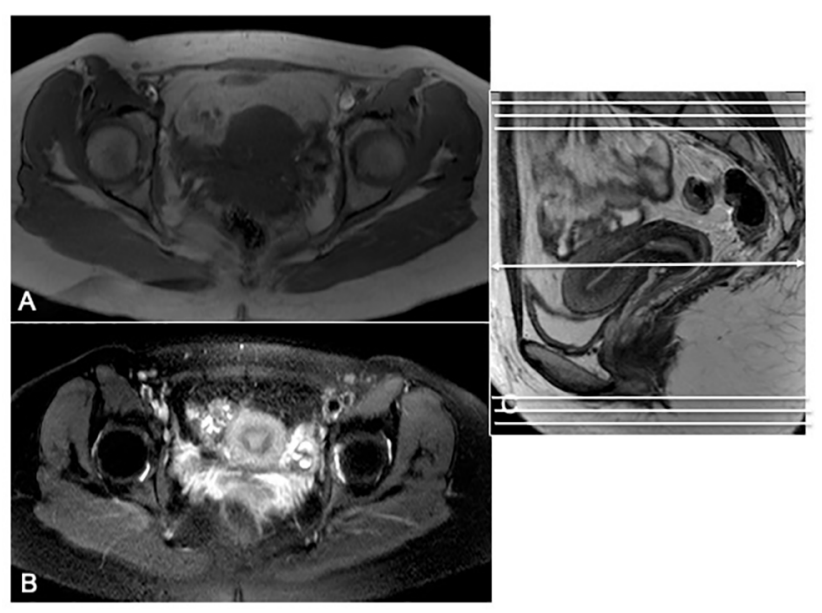

Fig. 1 Imaging sequences: axial T1W (A) and T2W fat saturated (B) images with large FOV covering entire pelvis in true axial plane as shown on Sagittal T2W image $(\mathbf{C})$ by white lines. The axial images are at the level of mid uterus as shown by double headed arrow in (C). The three lines at top and bottom delineate first and last slices. FOV, field of vision; T1W, T1-weighted; T2W, T2-weighted. 


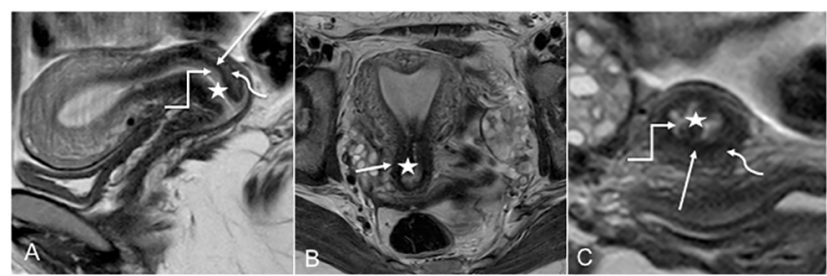

Fig. 2 Normal zonal anatomy: sagittal (A), oblique coronal (B) and oblique axial T2W (C) images through cervix show four zones from inner outwards: central hyperintense mucous (asterisk), high-signal intensity endocervical mucosa and glands (elbow arrow), hypointense fibrous stroma (straight arrow), and outer intermediate signal intensity loose stroma (curved arrow). T2W, T2-weighted.

DWI is also useful in assessing parametrial/pelvic invasion, nodal metastases, and recurrent/residual disease. Keriakos and Darwish used cut-off ADC value of $1.12 \times 10^{-3}$ with specificity of $100 \%$ and sensitivity of $87.5 \%$ to distinguish benign and cervical lesions. ${ }^{8}$

Routine MRI with DWI in combination can accurately distinguish between benign and malignant cervical lesions and is preferable to dynamic contrast MRI. ${ }^{9,10}$ Use of contrast is not necessary in staging of cervical cancer, as noncontrast images provide all the necessary information. ${ }^{7}$ Dynamic contrast-enhanced $\mathrm{T} 1$ fat-saturated images are mainly performed for endometrial carcinoma and are not part of routine protocol for staging of cervical carcinoma; however, these may be considered in evaluation of small cervical tumors, lesions with equivocal T2 findings, and in distinguishing tumor recurrence from posttreatment changes. ${ }^{11,12}$

\section{Normal Magnetic Resonance Imaging Anatomy}

Cervix on T2W images shows the following distinct zones from within outside [ - Fig. 2]:

- Zone 1: central hyperintense mucous in cervical canal.

- Zone 2: high-signal intensity endocervical mucosa and glands (contains numerous folds and clefts as the plicae palmate). Combined thickness of zones 1 and 2 is 2 to $3 \mathrm{~mm}$.

- Zone 3: hypointense fibrous stroma is 3- to 8-mm thick.

- Zone 4: outer intermediate signal intensity of loose stroma.

On T1W images, cervix appears as intermediate signal intensity structure without clear visualization of its zonal anatomy. ${ }^{4}$

The uterine corpus is smaller than the cervix in premenstrual girls ( - Fig. 3), whereas after menopause, uterus as a whole is smaller and atrophied with cervical length almost equal to uterine body ( - Fig. 4). ${ }^{2}$ Postoperative low-segment caesarean section (LSCS) scar is seen a thin-linear T2 hyperintense signal with associated muscular loss and thinning of anterior uterine wall ( $\mathbf{- F i g . 5}$ ).

\section{Pathologies of Cervix \\ Congenital Anomalies}

Uterus, cervix, fallopian tubes, and upper two-thirds of vagina arise from paired Müllerian ducts which eventually undergo fusion and resorption in utero. Any disruption

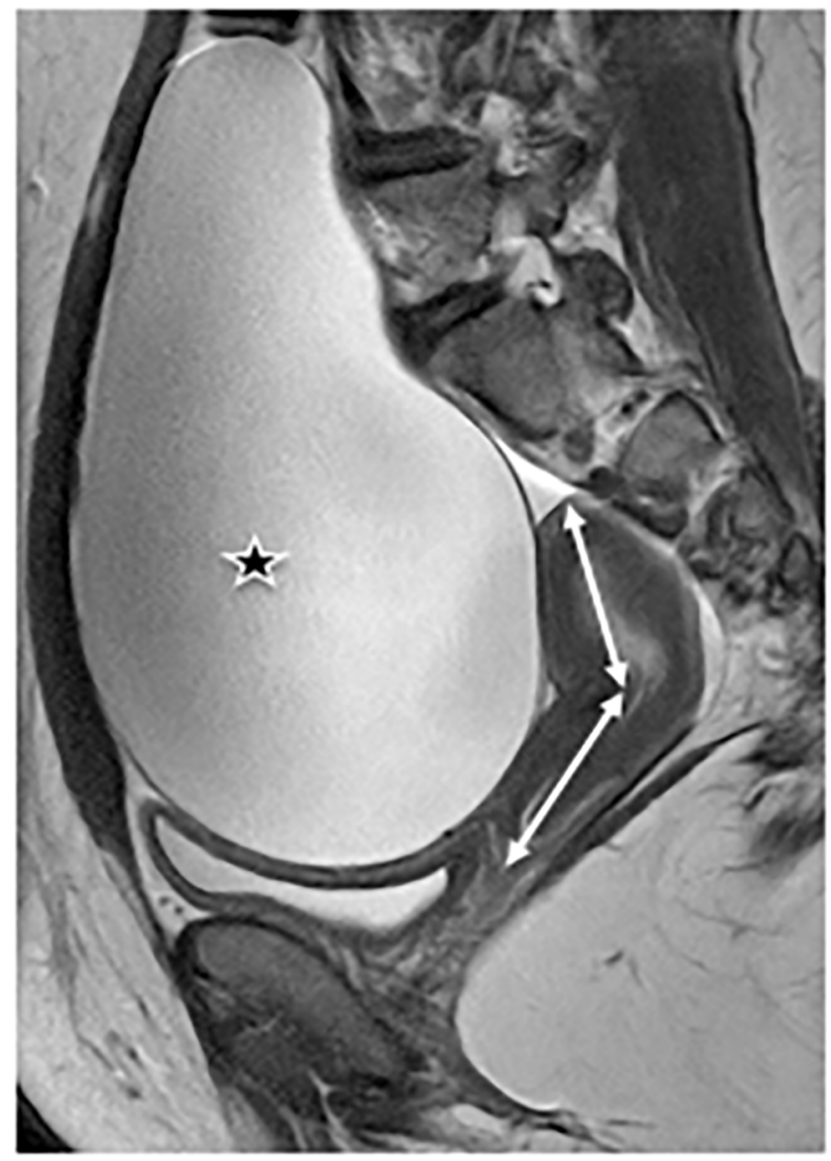

Fig. 3 Normal anatomy of infantile cervix: sagittal T2W image of 12-year-old girl showing length of infantile cervix is longer than body of uterus (double-headed arrow). Incidentally seen is large ovarian cyst (asterisk) displacing uterus posteriorly. T2W, T2-weighted.

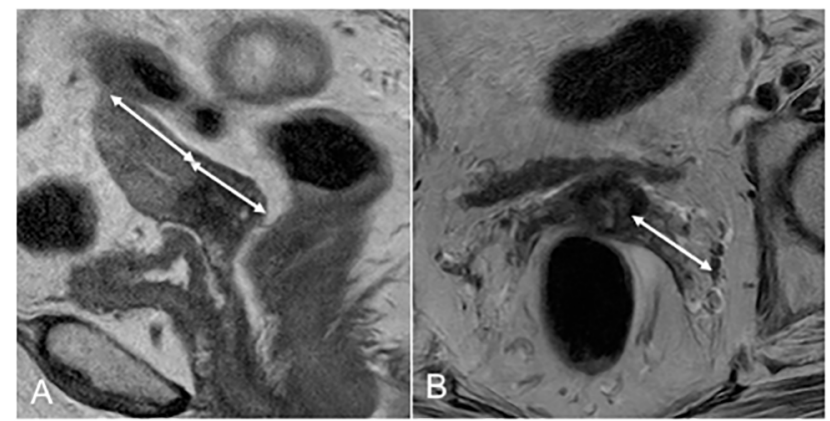

Fig. 4 Normal anatomy of postmenopausal uterus: sagittal (A) and axial (B) T2W images in 65-year-old female showing small atrophic uterus and cervix (double-headed arrow). The length of cervix is almost same as that of uterine body. T2W, T2-weighted.

in this process results in a spectrum of congenital anomalies termed as Müllerian duct anomalies (MDA). ${ }^{13}$ MRI is commonly used for in clinical practice for confirmation when these anomalies are suspected on ultrasonography or hysterosalpingography. ${ }^{14}$

The most widely accepted classification of MDAs is of the American Society for Reproductive Medicine system (-Table 1). This classification is a framework and not all anomalies completely fit into its seven categories. ${ }^{15}$ 


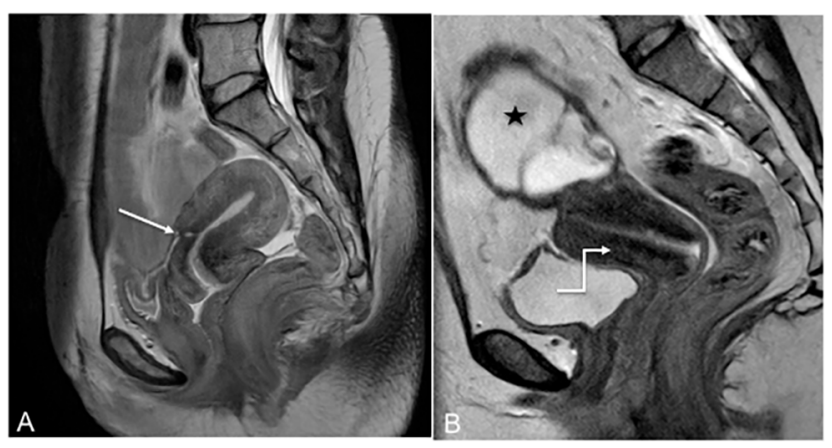

Fig. 5 Postsurgical cervix: normal appearance of uterus in (LSCS): sagittal (A) T2W images shows thin oblique T2W hyperintense LSCS scar (arrow). Subtotal hysterectomy for endometriosis in another 40-year-old female. Sagittal (B) T2W image shows cervix (arrow), however body of uterus and fundus are not seen due to surgery. Residual right adnexal endometriotic lesion (asterisk). T2W, T2-weighted.

Embryogenesis: female genital tract development occurs in three main stages, that is, ductal development, ductal fusion, and ductal degeneration. Hence, the anomalies are also characterized due to nondevelopment, nonfusion, and nondegeneration. ${ }^{16}$ We divided the cervical anomalies as seen on MRI into three groups: aplasia or hypoplasia of cervix, cervical duplication, and septum in cervix (-Table 2).

1. Agenesis or hypoplasia: these anomalies occur when there is early failure of ductal development. Mayer-RokitanskyKuster-Hauser syndrome is characterized by agenesis of proximal vagina, cervix, and uterus with normal ovaries very well seen on MRI ( - Figs. 6 and 7).They present with primary amenorrhea. Few cases of Turner's syndrome (partial or complete absence of X chromosome [45 XO]) can rarely have Müllerian agenesis with absent ovaries. Usual MRI findings in Turner's syndrome include well-formed uterus, cervix, and vagina which are smaller in volume (hypoplastic) with streak ovaries ( - Fig. 8). ${ }^{17}$ Unicornuate uterus (class II) is characterized by normal development of one horn and partial or complete nondevelopment of other horn. The rudimentary horn, if present, may be without uterine cavity or in presence of cavity may be communicating or not communicating with the normal side. MRI shows a small curved unicornuate uterus and small cervix with normal zonal anatomy seen off midline. A noncommunicating rudimentary horn may show presence of hematometra and hematosalphinx secondary to endometriosis ( - Figs. 9 and 10) ${ }^{13}$

Table 2 Cervical anomalies based on MRI appearance

\begin{tabular}{|l|l|}
\hline MRI appearance & MDA class \\
\hline $\begin{array}{l}\text { Absent or hypoplastic } \\
\text { cervix }\end{array}$ & Includes classes I and II MDA \\
\hline Duplication of cervix & Includes classes III and IV MDA \\
\hline Septum in cervix & Class V MDA \\
\hline
\end{tabular}

Abbreviation: MDA, Müllerian duct anomalies; MRI, magnetic resonance imaging.
Table 1 Classification of MDAs by American Society for Reproductive Medicine system

\begin{tabular}{|c|c|}
\hline \multirow[t]{6}{*}{ Class I } & $\begin{array}{l}\text { Segmental agenesis and variable degrees of } \\
\text { uterovaginal hypoplasia }\end{array}$ \\
\hline & la: vaginal \\
\hline & Ib: cervical \\
\hline & Ic: fundal \\
\hline & Id: tubal \\
\hline & le: combined \\
\hline \multirow[t]{5}{*}{ Class II } & $\begin{array}{l}\text { Unicornuate uterus which is characterized by } \\
\text { partial or complete unilateral hypoplasia }\end{array}$ \\
\hline & Ila: communicating rudimentary horn \\
\hline & Ilb: noncommunicating rudimentary horn \\
\hline & Ilc: no cavity \\
\hline & Ild: no horn \\
\hline Class III & $\begin{array}{l}\text { Uterus didelphys in which duplication of the } \\
\text { uterus results from complete non-fusion of the } \\
\text { Müllerian ducts. }\end{array}$ \\
\hline \multirow[t]{3}{*}{ Class IV } & $\begin{array}{l}\text { Bicoruate uterus which is characterized by } \\
\text { incomplete fusion of the superior segments of the } \\
\text { uterovaginal canal }\end{array}$ \\
\hline & IVa: complete \\
\hline & IVb: partial \\
\hline \multirow[t]{3}{*}{ Class V } & $\begin{array}{l}\text { Septate occurs due to nonresorption of uterovag- } \\
\text { inal septum }\end{array}$ \\
\hline & Va: complete \\
\hline & Vb: partial \\
\hline Class VI & $\begin{array}{l}\text { Arcuate results from near complete resorption of } \\
\text { the septum }\end{array}$ \\
\hline Class VII & DES associated uterine anomalies \\
\hline
\end{tabular}

Abbreviation: MDA, Müllerian duct anomalies.

2. Duplication of cervix: this can occur in uterus didelphys (class III) which is complete failure of fusion resulting in duplication of uterine horns, cervix, and proximal vagina and MRI shows duplicated two uteri, two cervices separated by normal myometrium ( - Fig. 11). Duplicated proximal vagina may be associated with transverse septum resulting in hematocolpos. Bicornuate uterus (class IV) which is partial failure of fusion and may be associated with duplicated cervix when muscular septum extends up to external os (bicornuate bicollis) or single cervix when septum is seen up to internal os (bicornuate unicollis).

3. Septum in cervix: this is seen in septate uterus (class VI) which the most common congenital uterine anomaly occurring due to partial or complete nonreabsorption of the uterovaginal septum. The septum can be fibrous or muscular. Septate uterus is characterized by convex external fundal contour and apex of external fundal contour is more than $5-\mathrm{mm}$ above interostial line to differentiate from fusion anomalies. Intercornual distance of less than $4.0 \mathrm{~cm}$ has been used to distinguish a septate from a bicornuate uterus. ${ }^{18}$ 


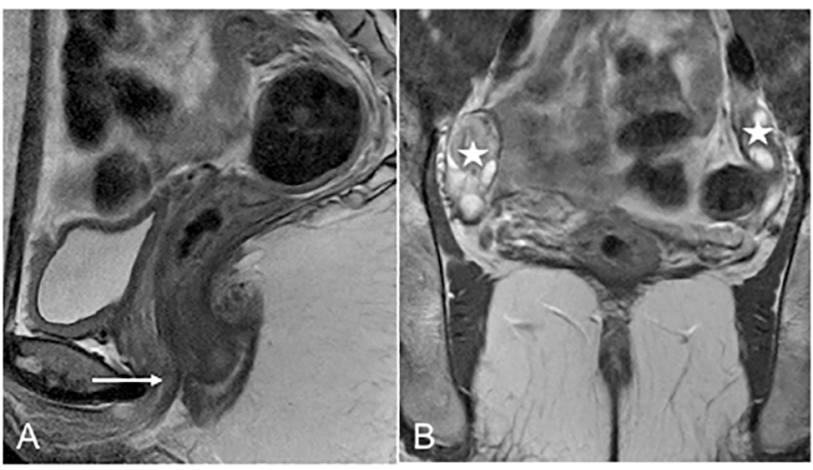

Fig. 6 Congenital: uterine and cervical aplasia: sagittal (A) and axial (B) T2W images in 18-year-old girl with primary amenorrhea shows complete absence of uterus including cervix. Lower vagina is seen (arrow). Both ovaries appear normal with multiple follicles (asterisk). These findings are suggestive of Meyer-Rokitansy-Kuster-Hauser syndrome. T2W, T2-weighted.
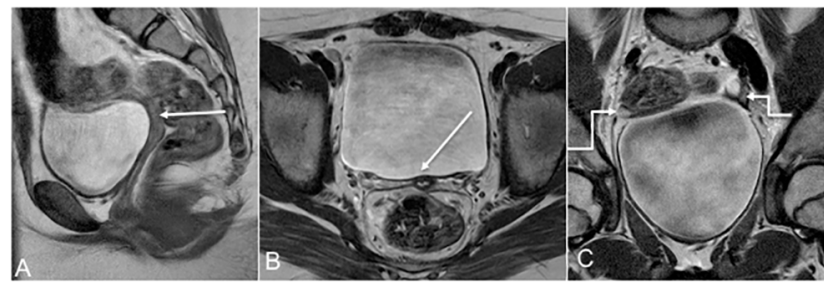

Fig. 7 Congenital: cervical hypoplasia: sagittal (A), axial (B), and coronal (C) T2W images in a 14-year-old girl with primary amenorrhea shows complete absence of uterus. Small hypoplastic cervix and vagina are visualized (arrow). Both ovaries appear normal with multiple follicles (elbow arrows). T2W, T2-weighted.

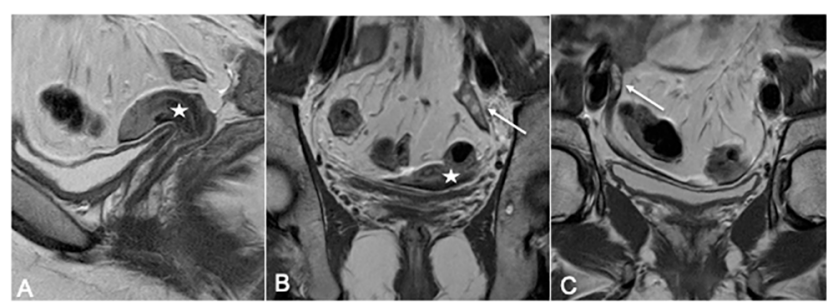

Fig. 8 Turner's syndrome: sagittal (A) and coronal (B and C) T2W images in a 26-year-old female with known Turner's syndrome show well-formed uterus and cervix (asterisk); however, these are small in size. Both the ovaries are identified and also show smaller volumes (arrow). T2W, T2-weighted.

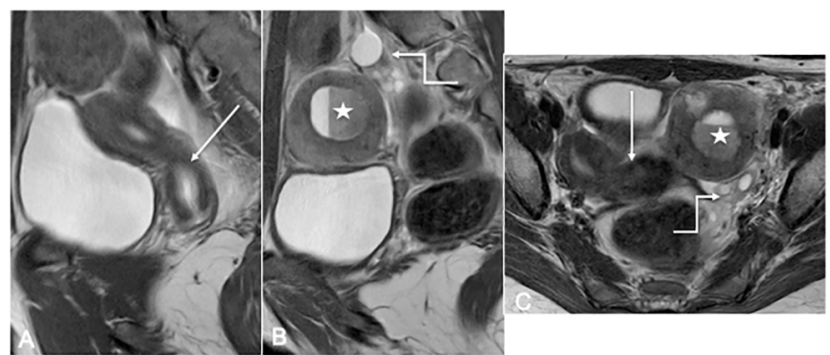

Fig. 9 Congenital: unicornuate uterus: sagittal (A and B) and axial (C) T2W images showing small unicornuate uterus with cervix on right side (arrow). Noncommunicating functional left rudimentary horn is seen showing blood-fluid level (asterisk). Ovaries are normal (elbow arrow). T2W, T2-weighted.

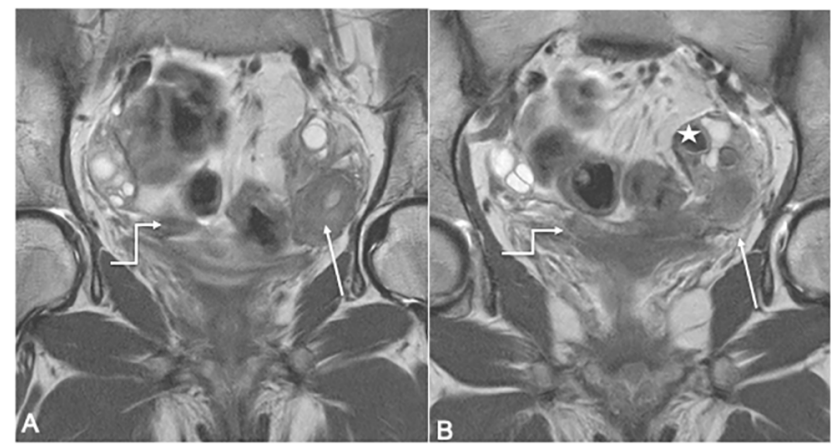

Fig. 10 Congenital: unicornuate uterus: coronal (A and B) T2W images showing small left unicornuate uterus (arrow). Few endometriotic cysts are seen in left ovary (asterisk). Rudimentary right horn (elbow arrow) is seen without endometrial cavity (nonfunctioning). T2W, T2-weighted.

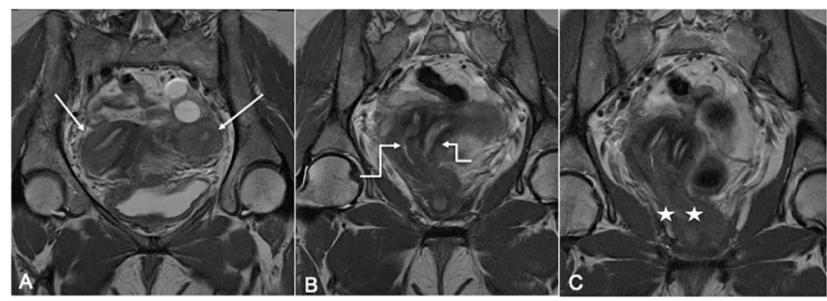

Fig. 11 Congenital: uterus didelphys: coronal $(\mathbf{A}-\mathbf{C}) \mathrm{T} 2 \mathrm{~W}$ images in a 37-year-old female showing two widely divergent uterine horns (arrows) separated by a deep fundal cleft. Two separate cervices are present (elbow arrow). Two vaginas (asterisk) are also seen with vertical septum. T2W, T2-weighted.

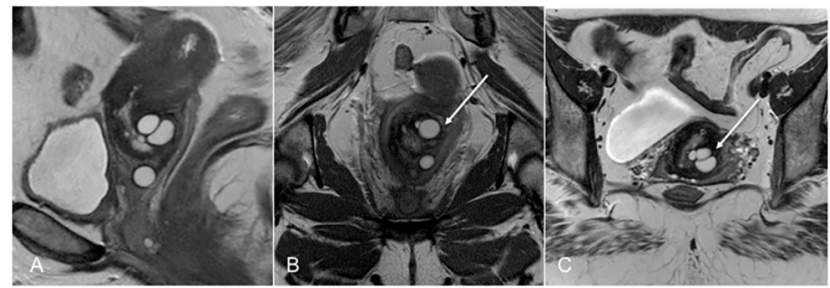

Fig. 12 Benign lesions: nabothian cysts: sagittal (A), coronal (B) and axial (C) images showing multiple well-defined cysts in anterior as well as posterior lips of cervix (arrow).

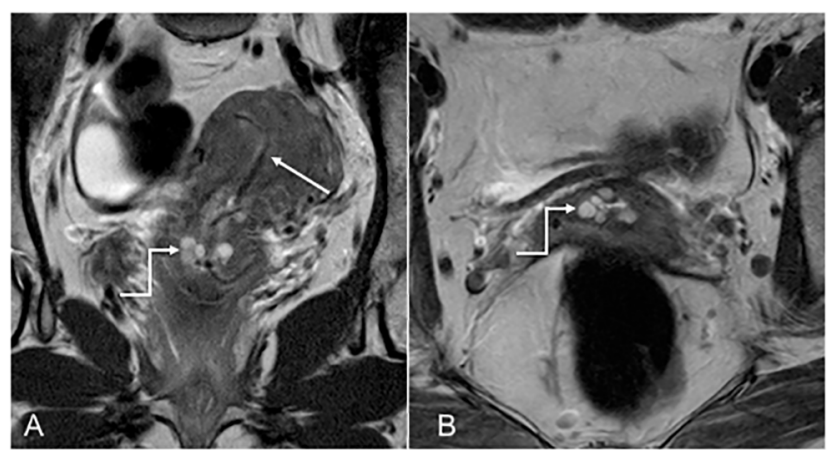

Fig. 13 Benign lesions: cervicitis: coronal (A) and axial (B) T2W images in a 38-year-old female with Mirena intrauterine device for 4 years had symptoms of pain and whitish vaginal discharge. MRI shows Intra uterine contraceptive device (arrow) in situ and multiple tiny cystic lesions in cervix (elbow arrow) suggestive of cervicitis. MRI, magnetic resonance imaging; T2W, T2-weighted. 


\section{Benign Lesions}

Nabothian cysts: these are retention cysts in cervix, formed as a result of healing of chronic cervicitis. In chronic cervicitis, there is proliferation of squamous epithelium which covers the columnar epithelium. Mucus secreted by columnar epithelium cannot be extruded out and results in formation of retention cyst. These are usually 2 to $10 \mathrm{~mm}$ in size and located on surface of endocervix; occasionally, they may be larger in size. ${ }^{7}$ Incidentally seen on MRI, these appear as well-defined small cystic lesions having intermediate or slightly high signal on T1W and very high on T2W images (-Fig. 12). It may be a single-cyst or multiple-cystic lesion, located in endocervical lesion and occasionally extending into deep cervical stroma resulting in enlargement of cervix. ${ }^{9}$ Larger cysts can cause pressure symptoms due to compression of urinary bladder/rectum, pelvic pain, or can rupture resulting in vaginal discharge. It is necessary to mention number and size of cysts in report as these are benign and assure patient and physician. There can be entrapment of nabothian cysts postsubtotal hysterectomy, resulting in formation of large cysts which can be symptomatic.

Tunnel cysts: tunnel cluster, a special type of nabothian cyst, is characterized by complex multicystic dilatation of the endocervical glands. ${ }^{7}$ These are benign, pseudoneoplastic glandular lesions of the cervix which are divided into two types: type $\mathrm{A}$ (noncystic) and type $\mathrm{B}$ (cystic). ${ }^{11}$ These are seen in multigravid females older than 30 years and result from subinvolution of previous episodes of physiologic hyperplasia of the endocervical mucosa, usually due to prior pregnancies. ${ }^{11}$ Jones et al found cytologic atypia in 14 cases; however, mitotic activity was absent or inconscpicous. Microscopically, these consists of lobulated proliferation of closely packed glands which are of small calibre and arranged around primary or secondary endocervical cleft. ${ }^{10}$ They are unrelated to cervical neoplasms and must be distinguished from adenocarcinoma and adenoma malignum. ${ }^{19,20}$ Features of benign lesions are of smaller size, well-marginated cysts, absence of cervical stromal extension, and absence of soft tissue component and enhancement.

Cervicitis: uterine cervicitis, the most common gynecological diseases is characterized by inflammation of cervical epithelium, either squamous or columnar epithelium. Trichomonas vaginalis, Candida albicans, and herpes simplex virus cause inflammation of squamous epithelium of ectocervix, whereas Neisseria gonorrhoeae and Chlamydia trachomatis affect the columnar epithelium. Vaginal discharge with pelvic pain are the common presenting complaints. ${ }^{7}$ MRI is not indicated; however, if done, it may show some retention cysts in cervix which are non-specific ( - Fig. 13). It may also appear as multicystic lesion with hyperintense signal on T1W and T2W images due to presence of secretions/proteinaceous contents/blood products. Healing results in fibrosis often resulting in cervical stenosis.

Lobular endocervical glandular hyperplasia: this lesion usually occurs in women of reproductive age group; however, may occur in few postmenopausal women. ${ }^{19}$ It is an incidental finding, but can present as erosion or polyp with watery discharge being the presenting complaint. It is a benign hyperplastic lesion characterized by cystic dilatation of cervical glands.

On MRI, enlarged inner T2/DWI hypointense solid cervical stroma is observed along with central tiny cyst surrounded by multiple large cysts in periphery giving cosmos flower sign..$^{20,21}$ The MRI appearance closely mimics adenoma malignum and it may be extremely difficult to differentiate these on MRI alone. Presence of mild glandular atypia and gastrin mucin along with MRI findings of multicystic lesion with inner solid component showed accuracy of $92 \%$ in a study by Takatsu et $\mathrm{al}_{, 22}$ in comparison, solid lesion with atypical glandular cells was indicative of adenoma malignum or adenocarcinoma.

Cervical leiomyoma: these are extremely uncommon as compared with leiomyomas occurring in uterine body. Tiltman found cervical leiomyoma in $0.4 \%$ hysterectomies as compared with $64.6 \%$ in uterine myometrium. ${ }^{23}$ They may occasionally form polypoidal lesion and protrude into the cervical canal or vaginal canal and can cause maternal dystocia. They may also cause dysmenorrhea and hypermenorrhoea. ${ }^{7}$ On MRI, these appear as a well-defined, rounded, T2 hypo-/ isointense lesion showing homogenous enhancement centered on cervix. Cellular leiomyomas have hyperintense signal on T2W images. However, various types of degeneration result in altered signal intensity (-Figs. 14 and 15). Cervical leiomyomas may have unusual growth pattern, ill-defined border, and may enclose the cervical canal into the leiomyoma. ${ }^{23,24}$

Cervical polyps: cervical polyps are the most common cause of intermenstrual vaginal bleeding. Other presenting symptoms include menorrhagia, postcoital bleeding, postmenopausal bleeding, and vaginal discharge. Majority of these polyps are asymptomatic and incidentally detected on routine gynecological examination, or on ultrasound, or as a filling defect on hysterosalpingography. Hysteroscopy accurately determines the number, location and size of these polyps, and also can be therapeutic in hysteroscopic polypectomy. ${ }^{25}$

These are seen in premenopausal women and are associated with chronic inflammation. They may be pedunculated or sessile, well-circumscribed masses, with or without cysts filling the endocervical and vaginal canal. ${ }^{7}$ Histologically,

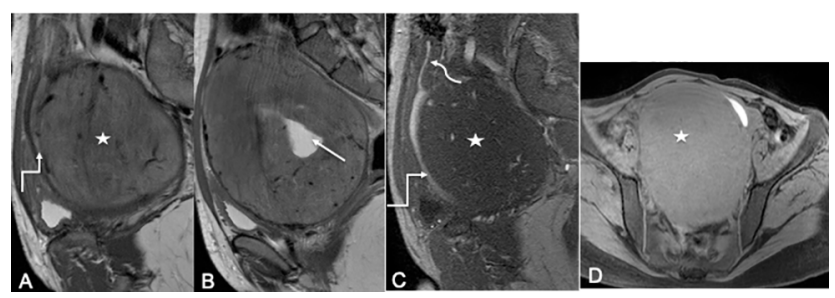

Fig. 14 Benign lesions: fibroid: sagittal T2W (A and B), T1W (C) and axial post contrast T1 fat-saturated (D) images in a 24-year-old female showing a large well-defined predominantly solid (asterisk) lesion with areas of necrosis (arrow) arising from posterior wall of cervix. It is isointense to myometrium, suggestive of fibroid. There is compression of cervical canal (elbow arrow). Note the uterus and endometrial cavity (curved arrow) separate from the lesion. T1W, T1-weighted; T2W, T2-weighted. 


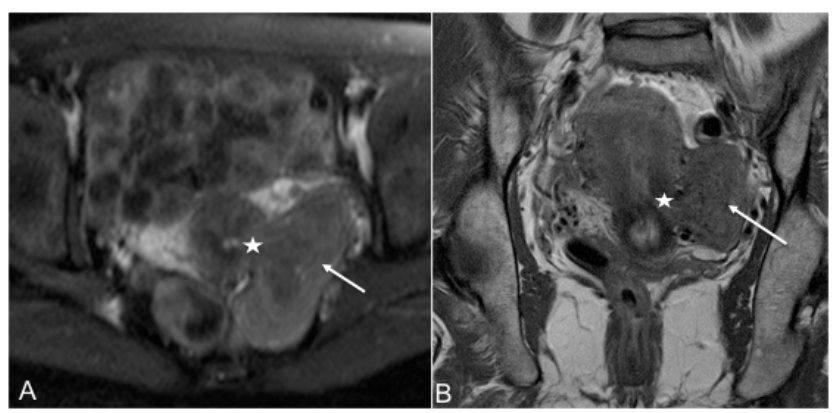

Fig. 15 Benign lesions: exophytic cervical fibroid: axial T2 fat-saturated (A) and coronal (B) T2W images in a 41-year-old female show a well-defined pedunculated lesion isointense to myometrium arising from left lateral wall (asterisk) of cervix suggestive of fibroid (arrow). T2W, T2-weighted.

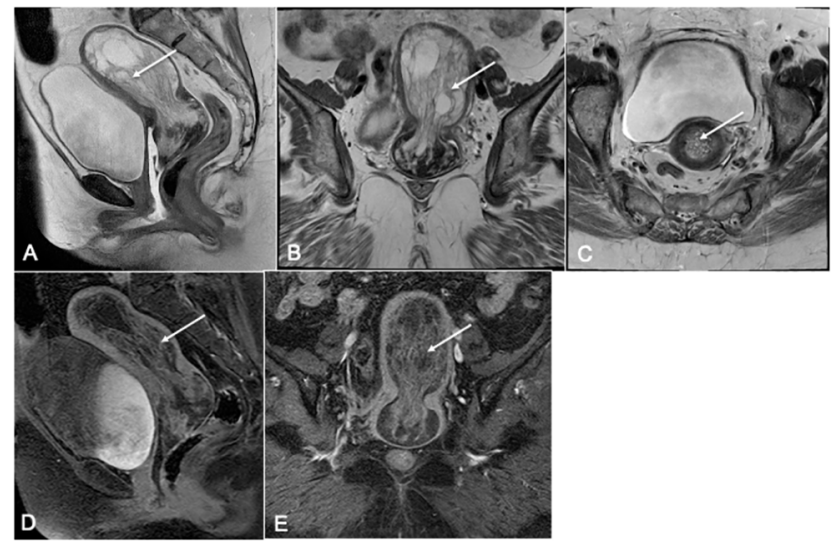

Fig. 16 Benign: cystic endometrial hyperplasia: sagittal (A), coronal (B) and axial (C) T2W and postcontrast (D and E) images in a 66-year-old female with postmenopausal bleeding, show heterogeneously enhancing polypoidal lesion distending the endometrial cavity and cervical canal. No restricted diffusion was seen (not shown). T2W, T2-weighted.

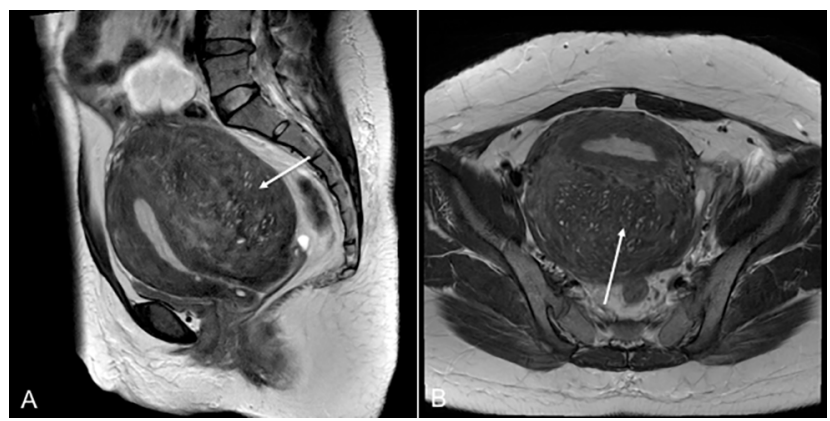

Fig. 17 Benign lesions: adenomyosis: sagittal (A) and axial (B) T2W images in a 44-year-old female show diffusely enlarged uterus with markedly thickened junctional zone appearing as a large ill-defined T2 hypointense area (arrow) along posterior uterine wall extending into cervix. Tiny $\mathrm{T} 2$ hyperintense foci of endometrial glands are seen within. These suggest adenomyosis. T2W, T2-weighted.

polyps encompass spectrum of various pathologies including endocervical/endometrial tissue with metaplasia. Other polypoidal cervical lesions include submucosal leiomyoma, malignancy, or blood clot. ${ }^{26}$ It has to differentiated from endometrial polyp by identifying the stalk with attached to the cervical wall; however, in $25 \%$ patients, both endometrial and cervical polyps may coexist. MRI accurately assesses cervical polyps or giant endometrial polyps extending into the cervical canal ( - Fig. 16).

Adenomyosis/endometriosis: adenomyosis is characterized by ectopic endometrial tissue in myometrium, whereas endometriosis is presence of functional endometrial glands and stroma outside the uterine cavity and myometrium. The functional endometrial tissue is responsive to hormonal changes and undergoes cyclic bleeding resulting in clinical and imaging findings. ${ }^{27}$ Adenomyosis is characterized by focal or diffuse thickening of junctional zone (>12 mm), presence of tiny T1, T2 hyperintense microcysts embedded in this thickening corresponding to islands of ectopic endometrial tissue and dilated glands, loss of junctional zone-outer myometrial interface, and adenomyoma which is focal consolidation of adenomyotic glands located within the myometrium. ${ }^{28,29}$ Adenomyoma may be seen as polypoidal mass protruding into uterine/cervical canal or as intramyometrial or subserosal mass. Other findings include globular enlargement of uterus, hyperintense linear striations radiating from endometrium to myometrium resulting in pseudowidening of endometrium, and adenomyotic cyst which is characterized by a hemorrhagic cyst surrounded by a solid wall. Adenomyosis has propensity to involve uterine fundus and is extremely rare in cervix. ${ }^{30}$ It is often seen as extension of adenomyosis from uterine fundus, body into cervix (-Figs. 17 and 18).

Isolated cervical endometriosis is considered rare. The incidence of cervix endometriosis has been reported to be between 1.6 and $2.4 \%$, and it is often a retrospective diagnosis on histopathology. It occurs usually in women of reproductive age group; however, Park et al reported a case of cervical endometriosis in a postmenopausal woman without hormonal therapy. ${ }^{31}$ It may be asymptomatic or presents with postcoital bleeding/intermenstrual bleeding, rarely with severe vaginal hemorrhage. ${ }^{32}$ Cervical endometriosis may occur in patients without any previous history of any traumatic cervical procedures like vaginal delivery, curettage, cone biopsy, loop excision procedure, electrocautery, or cryotherapy. ${ }^{33}$ In a case series by Wang et al, $84.8 \%$ patients with cervical endometrosis had either vaginal deliveries or curettage procedure. ${ }^{34}$ Cervical endometriosis may cause abnormal smear mimicking precancerous or cancerous lesions. ${ }^{35}$ Sometimes cervical endometriosis may present with cystic or polypoidal cervical mass. ${ }^{36}$ Endometriotic deposits may involve the serosal surface of uterus extending to cervix. There may be associated involvement of broad and round ligaments which appear thickened and nodular on imaging. Deep endometriotic lesions may involve the retrocervical region (above attachment of vaginal cuff to posterior cervix), rectovaginal septum, uterosacral ligaments, posterior vaginal fornix, and anterior rectal wall. On MRI, these regions show an ill-defined soft-tissue thickening having T2-hypointense signal. Endometriotic foci show T1-hyperintense foci, and solid glandular tissue shows variable enhancement on postcontrast images. ${ }^{36}$ 


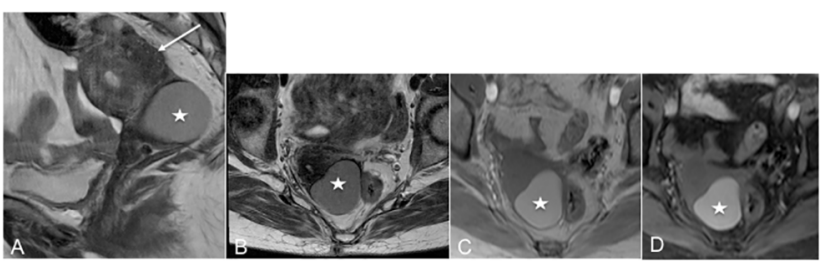

Fig. 18 Benign lesions: endometriotic cyst: sagittal (A), axial T2W (B), T1W (C) and T1 fat-saturated (D) images in a 60-year-old female show a well-defined partially exophytic lesion arising from left lateral wall of cervix. The lesion is hyperintense on $\mathrm{T} 1$ fat saturated images and mildly hypointense on $\mathrm{T} 2 \mathrm{~W}$ images suggestive of hemorrhagic contents (asterisk). Focal adenomyoma is also seen along posterior uterine wall (arrow). T1W, T1-weighted; T2W, T2-weighted.

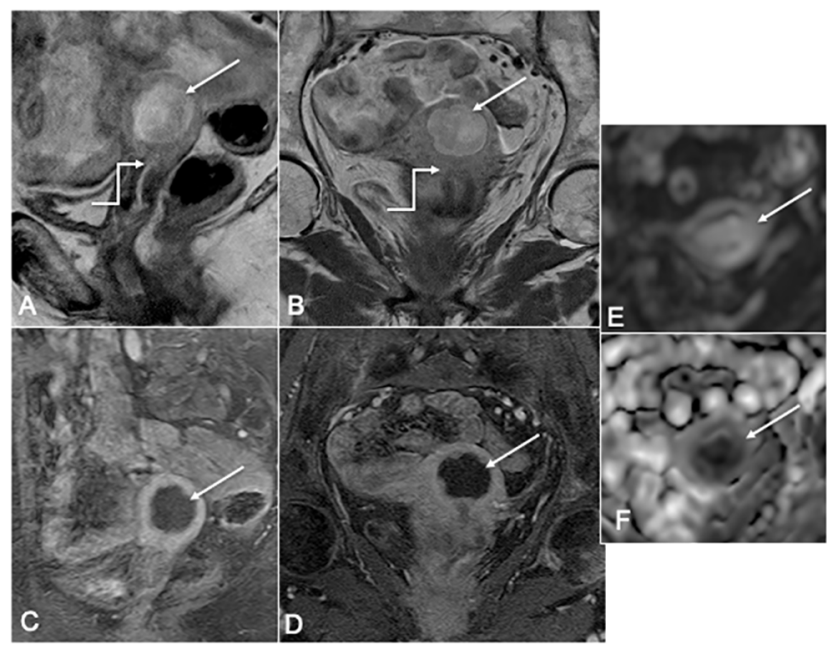

Fig. 19 Benign: cervical stenosis: sagittal and coronal T2W (A and B) and contrast-enhanced T1 fat saturated (C and D) and DWI (E) and ADC (F) images in a 99-year-old female show collection in endometrial cavity (arrow) due to obstruction at the level of internal os (elbow arrow). This collection shows restricted diffusion suggestive of pyometra. No obvious mass is seen in cervix. Dilation and curettage revealed cervical stenosis with adhesions and pyometra was drained. DWI, diffusion-weighted image; T2W, T2-weighted.

Cervical stenosis: this is characterized by pathological narrowing of cervix and can be congenital or secondary to benign conditions like chronic infection, endometriosis, trauma, postprocedure or instrumentation or radiotherapy, fibroid or polyp, senile atrophy, and malignant lesions like endometrial or cervical cancers. The stenosis may result in amenorrhea, hydrometra, pyometra, or hematometra. Cervical stenosis also results in infertility due to inability of sperms to enter into uterus. ${ }^{37}$ Role of MRI is to exclude pathological causes of cervical stenosis ( - Fig. 19). Usually, the symptoms would be bleeding, vaginal discharge or acute pain, secondary to etiology causing stenosis. Rarely, it can be asymptomatic as reported by Guven et al in case of senile cervical stenosis. ${ }^{38}$

\section{Malignant}

Carcinoma cervix: cervical cancer is the fourth most common cancer in women worldwide, and the second most common in low- and middle-income countries, ${ }^{39}$ resulting in large morbidity and mortality. MRI is extremely useful in early diagnosis, staging of cervical cancer, and evaluating posttreatment status.
Cervical tumors originate at squamocolumnar junction which in younger women exists at portio vaginalis, hence cancers tend to occur at portio vaginalis with exophytic growth. In older women, squamocolumnar junction exists at cervical canal and hence the tumors arise in the cervical canal, are invasive, and spread externally to involve the cervical stroma and then parametria. There is often obstruction of cervical canal with resultant hydro-/hematometra. Histologically, squamous cell carcinoma accounts for 75 to $90 \%$ of all cervical cancers. Adenocarcinoma, adenoid cystic, adenoid basal, and small-cell carcinoma form a remainder of cervical cancers. These tumors typically appear hypointense on T1W, hyperintense on T2W images, and show restricted diffusion with high signal on DWI and low signal on ADC maps. Carcinoma of cervix usually spreads to parametrium and to the uterine wall through the lymphatic invasion or deep myometrium invasion.

Staging of cervical carcinomas: the revised FIGO classification (2018) is used presently which considers use of any imaging modality and/or pathological findings in deciding the stage of tumor. Earlier FIGO classification (2009) was based only on clinical assessment which is observer dependent with limitations in correctly detecting parametrial involvement/pelvic side wall invasion and size of tumor. Lymph node status also was not included in the earlier classification which is very important in staging of disease. ${ }^{40}$ Due to these fallacies, revised FIGO classification (2018) was made. ${ }^{41}$ The modifications are as follows:

- Stage IA: lateral extension measurements are removed.

- Stage IB: now has three subdivisions instead two.

- Stage III: it also has three subdivisions with IIIC indicating involvement of pelvic or retroperitoneal adenopathy which are diagnosed on radiology $(r)$ or pathology $(p)$. The notations " $\mathrm{r}$ " and " $\mathrm{p}$ " are to be recorded.

- Stage I: tumor is confined to cervix.

- Stage IA: microscopic disease which cannot be evaluated on MRI.

- IA1: Microscopic disease invasion $<3 \mathrm{~mm}$ in depth.

- IA2: Microscopic disease invasion $>3 \mathrm{~mm}$ and $<\mathrm{zmm}$ in depth

- Stage IB: invasive carcinoma with measured deepest invasion $\geq 5 \mathrm{~mm}$ (-Figs. 20 and 21)

- IB1: invasive carcinoma $\geq 5 \mathrm{~mm}$ depth of stromal invasion and $<2 \mathrm{~cm}$ in greatest dimension.

- IB2: invasive carcinoma $\geq 2 \mathrm{~cm}$ and $<4 \mathrm{~cm}$ in greatest dimension.

- IB3: invasive carcinoma $\geq 4 \mathrm{~cm}$ in greatest dimension.

Clinically visible lesion confined to cervix. On MRI, these tumors appear hyperintense relative to cervical stroma. The T2-hypointense rim of cervical stroma is maintained. When the thickness of this low signal intensity rim is greater than $3 \mathrm{~mm}$, the hypointense rim sign is very specific (96-99\%) for excluding parametrial invasion thus the lesion is called definitive IB. ${ }^{42}$ 


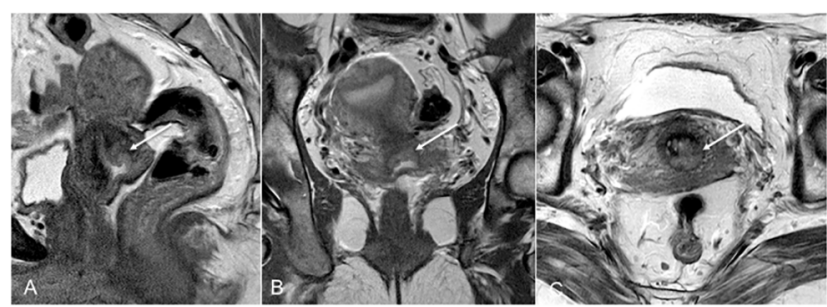

Fig. 20 Malignant: cervical carcinoma stage IB1: sagittal (A), coronal (B) and axial (C) T2W, in a 39-year-old female show small $(<2 \mathrm{~cm}$ ) endophytic lesion involving posterior lip of cervix (arrow). T2 hypointense outer fibrous stromal rim is preserved. T2W, T2-weighted.

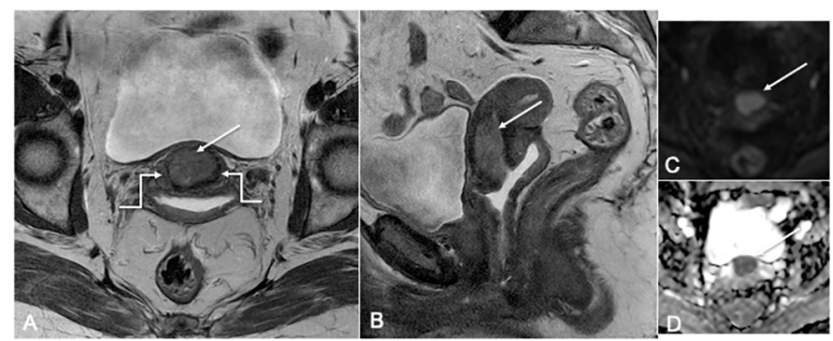

Fig. 21 Malignant: cervical carcinoma stage IB3: axial (A), sagittal (B) T2W, diffusion (C) and ADC maps (D) in a 55-year-old female show a well-defined T2 hyperintense lesion involving anterior lip of cervix and showing restricted diffusion (arrow). The lesion is $>4 \mathrm{~cm}$ in cranio-caudal extent. Outer T2 hypointense rim of stroma is maintained (elbow arrow). No extension into upper vagina or parametria infiltration seen. T2W, T2-weighted.

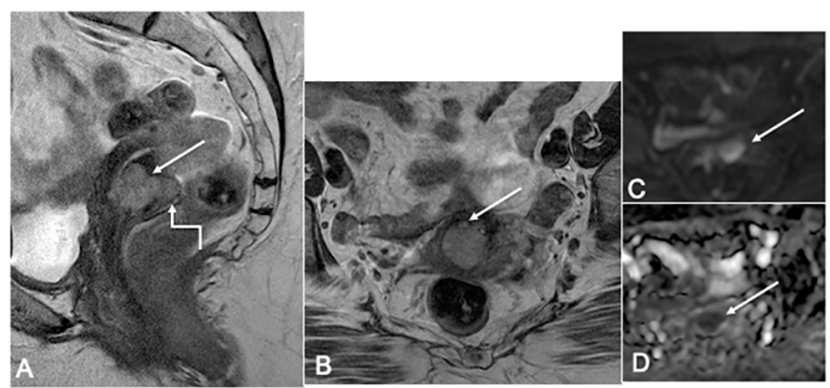

Fig. 22 Malignant: cervical carcinoma stage II A1: sagittal (A), axial (B) T2W, diffusion (C) and ADC maps (D) in a 65-year-old female show a well-defined hyperintense lesion (arrow) less than $4 \mathrm{~cm}$ in size involving posterior lip of cervix and adjacent vaginal fornix. The outer T2 hypointense signal of cervical stroma is maintained. No parametrial invasion seen. T2W, T2-weighted.

Size is important in patient management as few centers offer chemoradiation for bulky tumors instead of surgery.

- Stage II: invasion beyond uterus but not to pelvic sidewalls or lower third vagina.

- Stage IIA: upper two-thirds of vagina is involved; however, no parametrial invasion. On MRI, low signal intensity vaginal wall or fornix is disrupted and is contiguous with cervical tumor (-Figs. 22 and 23).

- IIA1: tumor $<4 \mathrm{~cm}$.

- IIA2: tumor $\geq 4 \mathrm{~cm}$.
- Stage IIB: tumor invades the parametrium without reaching up to pelvic wall (-Fig. 24).

On MRI, the outer T2-hypointense cervical stroma is disrupted with tumor extending into parametrium. Other findings include spiculated tumor-parametrial interface, soft tissue invading the cardinal, and uterosacral ligaments, encasement of periuterine vessels and pulling of cervix to the side of invaded parametrium. In tumors with such full-thickness stromal invasion, but no parametrial mass, parametrial invasion is present in 40 to $73 \%{ }^{42}$ However, occasionally in large tumors, it may be difficult to differentiate peritumoural edema from actual parametrial invasion. Presence of parametrial invasion is contraindication to surgery.

- Stage III: tumor extends to pelvic sidewall and/or involves the lower third of vagina and/or causes hydronephrosis/ non-functioning kidney and/or involves pelvic/para-aortic nodes.

- Stage IIIA: lower third of vagina is involved without pelvic wall invasion. On MRI, there is loss of lower signal intensity wall of lower vagina (-Figs. 25A and B ).

- Stage IIIB: tumor involves pelvic sidewalls or causes hydronephrosis/nonfunctioning kidney.

On MRI, the tumor infiltrates the cardinal ligaments and involves the pelvic muscles. Presence of tumor within $3 \mathrm{~mm}$ of internal obturator, levator ani, and pyriformis muscles or the iliac vessels. Infiltration into distal ureters with proximal hydroureteronephrosis may be seen.

- Stage IIIC: involvement of pelvic and/or paraaortic lymph nodes, irrespective of tumor size and extent (with "r" and "p" notations; - Fig. 26).

- IIIC1: pelvic lymph node metastasis only.

- IIIC2: para-aortic lymph node metastasis.

- Stage IV: tumor extends outside true pelvis or invades bladder or rectal mucosa.

- Stage IVA: tumor invades the rectal or vesical mucosa (-Figs. 27 and 28).

On MRI, it is seen as thickened walls with disruption of T2 hypointense wall with tumor nodules protruding into bladder/rectal lumen. Invasion of urinary bladder is more common than rectum due to relative bare area of bladder posteriorly below peritoneal reflection. Rectal involvement occurs via uterosacral ligaments. Contiguous involvement of rectum or bladder with loss of fat planes indicates serosal involvement. Bullous edema of bladder suggests nonspecific mucosal reaction due to impaired perfusion without definite invasion. MRI has very high negative predictive value of $100 \%$ in assessing bladder and rectal invasion. ${ }^{43}$

- Stage IVB: distant metastases. tumor involving organs outside true pelvis including paraaortic or inguinal nodes. Hematogenous spread of disease can occur to lung, liver, and bones. 


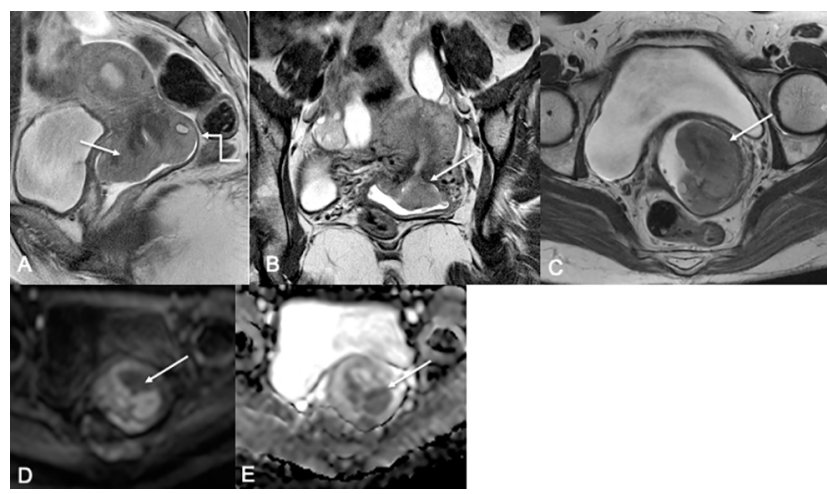

Fig. 23 Malignant: cervical carcinoma stage II A2: sagittal (A), coronal (B) and axial (C) T2W, diffusion (D) and ADC maps (E) in a 30-year-old female with vaginal spotting show an ill-defined polypoidal hyperintense mass involving the ectocervix (arrow) and protruding into vaginal lumen. The lesion shows restricted diffusion and also infiltrates the posterior vaginal fornix (elbow arrow). Both parametria are uninvolved. T2W, T2-weighted.

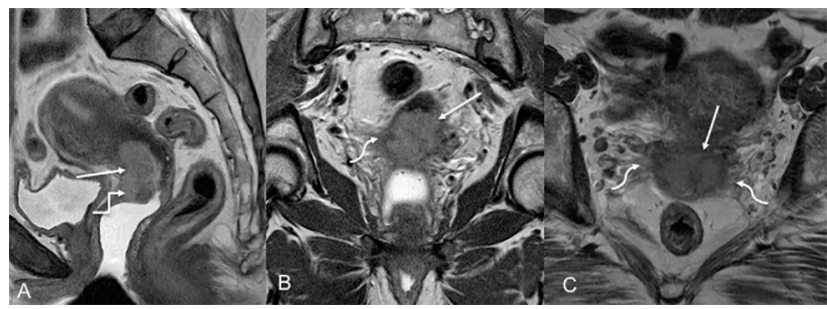

Fig. 24 Malignant: Cervical carcinoma Stage II B: Sagittal (A), coronal (B) and axial (C) T2W images in a 40-year-old female showing an ill-defined hyperintense mass in cervix (arrow) infiltrating upper one-third of anterior vagina (elbow arrow). Bilateral parametria are also infiltrated (curved arrow)
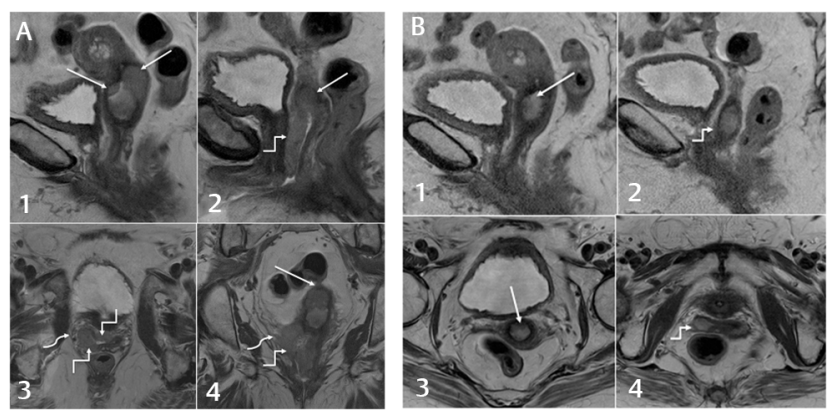

Fig. 25 (A 1) Malignant: cervical carcinoma stage IIIA: sagittal (1 and 2) and axial (3) and coronal (4) T2W images show a large heterogenous mass involving cervix (arrow) which also extends into anterior and right lateral wall of entire length of vagina (elbow arrow). (B) (1) Right paravaginal infiltration is also seen (curved arrow) (2) malignant: cervical carcinoma stage IIIA: post-three cycles of chemotherapy: sagittal (1 and $\mathbf{2}$ ) and axial ( $\mathbf{3}$ and $\mathbf{4}) \mathrm{T} 2 \mathrm{~W}$ images show significant reduction in the size of cervical (arrow) and vaginal lesions. Residual mass is seen in right lateral vaginal wall (elbow arrow). Note now the right paravaginal infiltration is not seen. $\mathrm{T} 2 \mathrm{~W}$, T2-weighted.

\section{Lymph Node Evaluation}

The cervical carcinoma first spreads to pelvic nodes, that is, parametrial then obturator, internal and external nodes, and common iliac nodes. Screening of abdomen is always

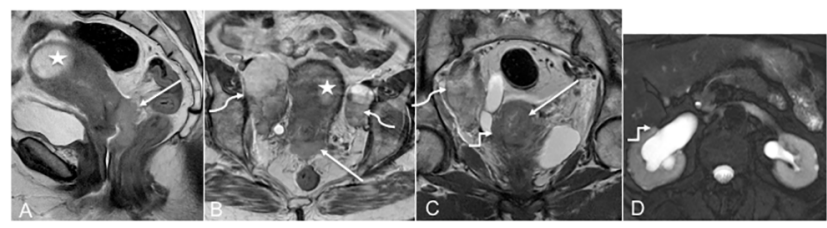

Fig. 26 Malignant: cervical carcinoma stage IIICr: sagittal (A), axial (B) and coronal (C) T2W pelvis images and axial T2 fat-saturated (D) image of kidneys show a large cervical mass infiltrating lower half of uterine body and upper vagina (arrow). The lesion results in cervical stenosis with hydrometra (asterisk). Encasement of right lower ureter results in moderate right hydroureteronephrosis (elbow arrow). Multiple large necrotic bilateral external iliac nodes are seen (curved arrow). T2W, T2-weighted.

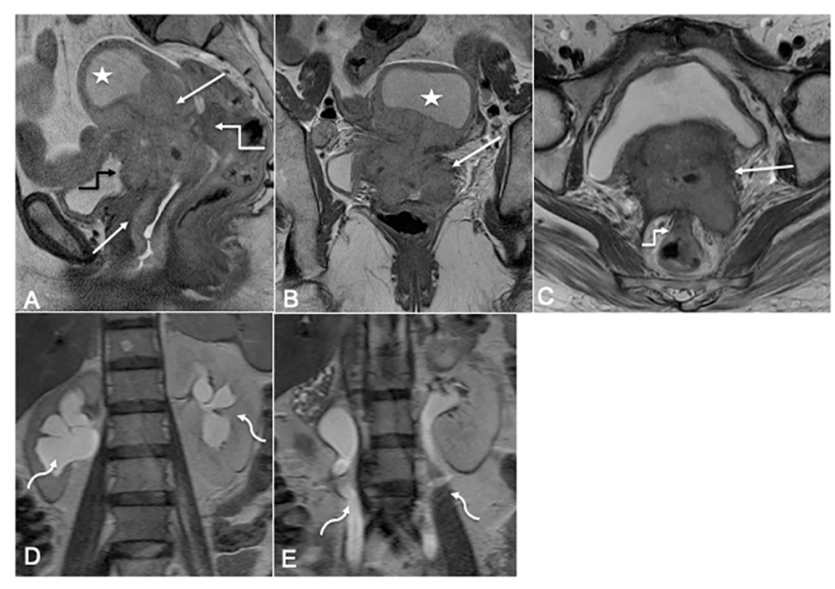

Fig. 27 Malignant: cervical carcinoma stage IV A: sagittal (A), coronal (B) and axial (C) T2W images of pelvis and coronal T2W images of abdomen ( $\mathbf{D}$ and $\mathbf{E}$ ) showing large cervical mass (arrow) infiltrating lower uterine body and almost entire vagina with hydrometra (asterisk). The mass also infiltrates anterior rectal wall (white elbow arrow) and posterior urinary bladder wall (black elbow arrow). Bilateral hydroureteronephrosis is seen (curved arrow). T2W, T2-weighted.

done in patients with carcinoma cervix to evaluate for para-aortic/retroperitoneal nodes, liver metastases.

Risk of nodal metastases increases with tumor size, depth of stromal invasion, lymphovascular invasion, and parametrial disease. ${ }^{44-46}$ MRI helps in assessment of size and morphology of the nodes. A length of $10 \mathrm{~mm}$ is considered to be the upper limit for short axis of normal nodes and $8 \mathrm{~mm}$ for rounded nodes. The diseased nodes have short-axis diameter of $>10 \mathrm{~mm}$, round shape, central necrosis, and perinodal infiltration. Necrosis is seen as small areas of T2-hyperintense signal in node. MRI and computed tomography (CT) have comparable overall accuracies in detecting nodal metastases $^{47}$; however, they cannot detect micrometastases in normal sized nodes and reactive enlargement without malignant involvement. Positron emission tomography (PET)-CT is more sensitive than CT alone or MRI and can also detect metastases in normal sized lymph nodes. ${ }^{48,49}$

The treatment of carcinoma cervix includes either surgery and/or radical radiotherapy with adjuvant chemotherapy depending on its stage..$^{50,51}$

Cervical stage IB1 or below can be treated with surgery or definitive radiotherapy. Advantages with primary surgery are preservation of ovaries avoiding early menopause, 


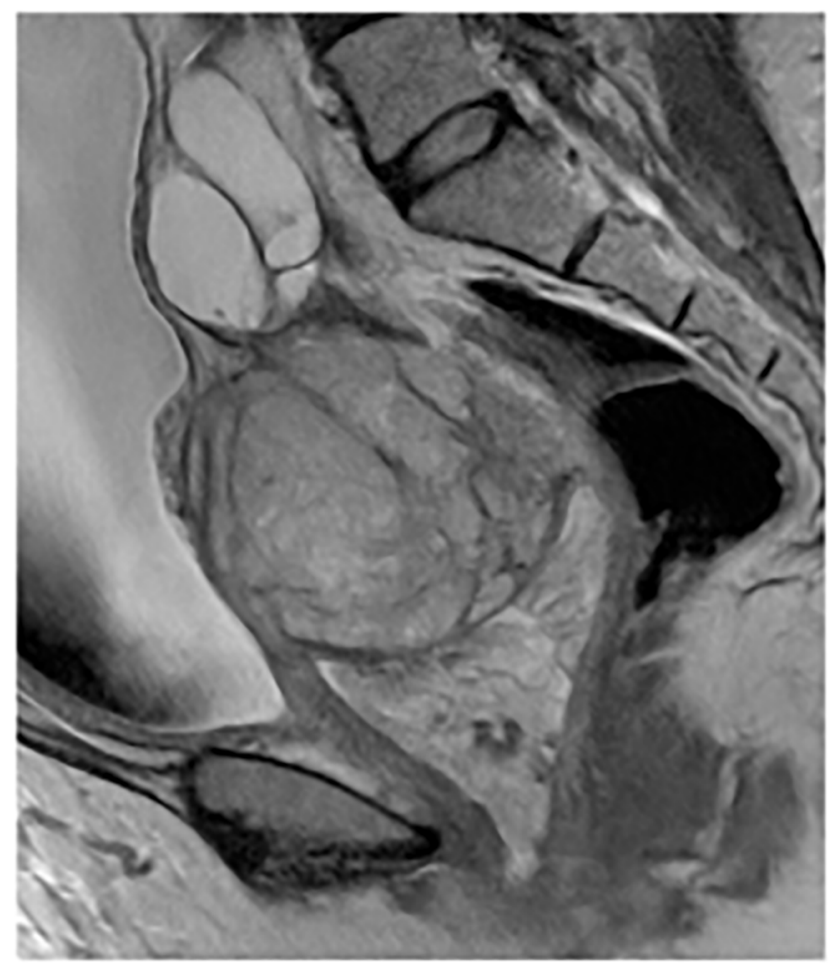

Fig. 28 Malignant: stump carcinoma cervix: sagittal (A) and axial (B and C) T2W images in a 45-year-old female showing a large heterogenous mass (arrow) involving uterine stump and extending into the vagina. The tumor also infiltrates the posterior urinary bladder wall (elbow arrow) and both vesico-ureteric junctions resulting in moderate hydroureteronephrosis (curved arrow). Mild right hydrosalpinx is also seen (asterisk). Patient had past history of subtotal hysterectomy. T2W, T2-weighted.

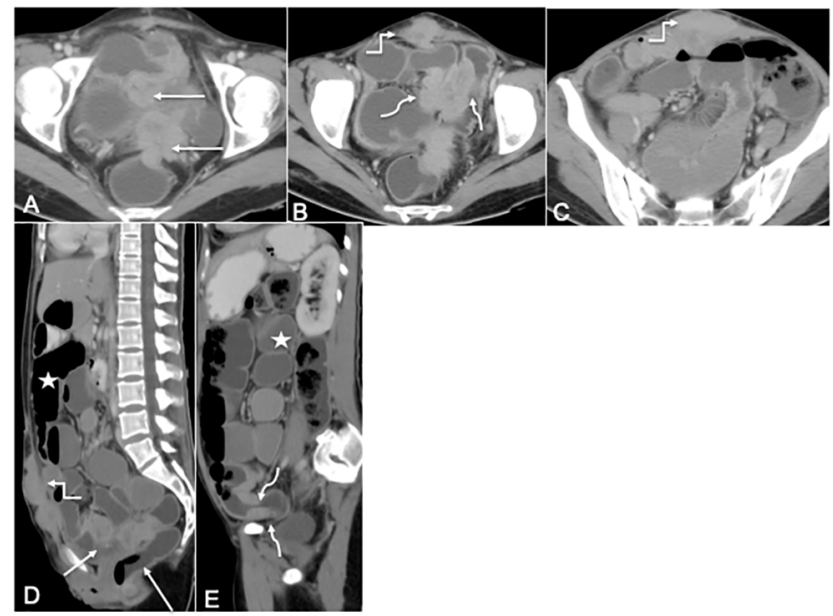

Fig. 29 Malignant: cervical carcinoma recurrence: axial (A-C) and sagittal (D and E) postcontrast CT scan images in a 45-year-old female treated case of carcinoma of cervix 4 years back show recurrent soft tissue mass at vaginal vault (arrow) infiltrating anterior rectal wall, at anterior abdominal wall at scar site (elbow arrow) and also involving distal ileum (curved arrow) with proximal dilated segments showing air- fluid levels (asterisk). CT, computed tomography.

preservation of sexual function due to less vaginal fibrosis and elimination of risk of radiation induced malignancy, hence considered in young women..$^{52}$ Radiotherapy can also be administered to elderly patients with multiple other

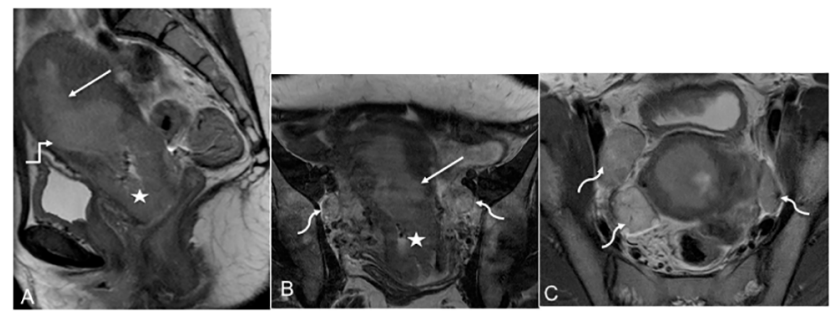

Fig. 30 Malignant: carcinoma endometrium extending into cervix: sagittal (A), coronal (B) and axial (C) T2W images showing an ill-defined T2 hyperintense soft tissue lesion (arrow) in endometrial cavity infiltrating more than half of anterior myometrium (elbow arrow). Inferiorly it involves endocervical canal (asterisk) and also infiltrates outer cervical stroma posteriorly. Bilateral necrotic external iliac and obturator nodes are seen (curved arrow). T2W, T2-weighted.

comorbidities, and to patients with extensive vaginal invasion that are predicted to experience severe urinary incontinence following surgery. Also, definitive radiotherapy is preferred in patients who are likely to require postoperative radiotherapy to avoid dual treatment related morbidities.

Patients with stage IA1 may be treated with cervical conization or total hysterectomy/simple hysterectomy/extrafascial hysterectomy. As the rate of pelvic nodal metastases is less than $1 \%$, lymphadenectomy is not recommended. However, if there is lymphovascular space invasion (LVSI), pelvic lymphadenectomy is considered with modified radical hysterectomy. ${ }^{53}$

Patients with stage IA2 are treated with modified radical hysterectomy and bilateral pelvic lymphadenectomy. Modified radical hysterectomy includes removal of uterus, cervix, medial parametrium, upper 1 to $2 \mathrm{~cm}$ of vagina, medial halves of uterosacral, and cardinal ligaments. ${ }^{53}$

Patients with stage IB1 are treated with radical hysterectomy or modified radical hysterectomy and pelvic lymphadenectomy. Radical hysterectomy includes removal of uterus, cervix, upper one-third of vagina, most of parametrial tissue up to pelvic wall, and removal as far as possible from the uterosacral ligaments. ${ }^{53}$

In a subset of patients with low-risk early-stage (IA2 and IB1) cervical carcinoma, rate of parametrial invasion is less than $1 \%$. Less radical surgical options of simple hysterectomy, simple trachelectomy, cervical conization with or without sentinel node biopsy, and pelvic nodal dissection may be considered in these patients. Low-risk early-stage cervical carcinoma criteria includes squamous carcinoma, adenocarcinoma, or adenosquamous carcinoma, tumor size $<2 \mathrm{~cm}$, stromal invasion $<10 \mathrm{~mm}$, and no lymph-vascular space invasion. However, conservative approach should be considered in setting of clinical trials and only after accurate information on histology, grade, depth of invasion, margin status, and lymphovascular space invasion is assessed. ${ }^{54}$

In stages IB2 and IIA1, either surgery or radiotherapy can be used for definitive treatment. For stages IB3 and IIA2 lesions, as there are higher chances of recurrence, surgery followed by adjuvant radiotherapy is recommended. Neoadjuvant chemotherapy followed by debulking surgery is another option in bulky early stage tumors (IB3 and IIA2). 
Early-stage cervical carcinoma (tumors < stage IIB) can also be treated with external beam radiotherapy plus brachytherapy. ${ }^{55}$

For advanced cervical carcinoma (IIB and more), chemoradiation is the optimal treatment. Surgery does not offer any additional survival benefit in these patients, increases the morbidity, and also delays radiotherapy. ${ }^{55}$

\section{Recurrence}

Tumor recurrence can be local involving the cervix or vaginal vault, regional involving the parametrium, pelvic side walls, pelvic nodes, rectum, urinary bladder or distant involving lung, liver, para-aortic, and inguinal lymph nodes. ${ }^{55}$ MRI due to higher soft-tissue resolution is helpful in determining recurrence versus posttreatment change. The recurrent mass appears lobulated, T2 hyperintense, and shows restricted diffusion with heterogenous enhancement, whereas fibrotic scar shows low signal on T2W and diffusion images ${ }^{56}$ (-Fig. 29). Posttreatment, the cervix becomes fibrotic and contracted along with restoration of normal low signal on T2W images, suggesting complete response to radiotherapy. The vesicovaginal and enterovaginal fistulas are most common fistulas associated with cervical cancer. These can occur due to recurrence or due to treatment related (postsurgery or postradiotherapy). MRI is useful in such cases, as it depicts exact location of fistula, single or multiple tracts, and associated with recurrence or fibrosis or pelvic adhesions. CT scan or PET-CT can help in detecting distant metastases. ${ }^{57}$

\section{Fertility Preserving Surgery}

In patients with smaller tumors at early stage (stage 1) and who desire to preservation of fertility, cervical conization or radical local excision of cervical tumor (trachelectomy) with pelvic lymphadenectomy can be performed. Radical trachelectomy includes radical local excision of cervix with adjacent parametria, laparoscopic pelvic nodal dissection, and reanastomosing the uterine isthmus to proximal vagina. ${ }^{58}$ Radical trachelectomy can be performed vaginally or transabdominally ${ }^{57}$ ( - Table 3).

MRI, with sensitivity of $100 \%$ and specificity of $96 \%$, helps in assessing the distance of tumor from the internal os. ${ }^{59}$

These patients also need follow-up MRI scans to detect early recurrence of tumor. The most common MRI finding post trachelectomy is uterovaginal anastomosis, posterior puckering of the vaginal wall representing "'neo-fornix."

Table 3 Eligibility criteria for trachelectomy

\begin{tabular}{|l|l|l|}
\hline \multirow{2}{*}{$\begin{array}{l}\text { Eligibility } \\
\text { criteria }\end{array}$} & \multicolumn{2}{|c|}{ Type of trachelectomy } \\
\cline { 2 - 3 } & $\begin{array}{l}\text { Vaginal radical } \\
\text { trachelectomy }\end{array}$ & $\begin{array}{l}\text { Abdominal radical } \\
\text { trachelectomy }\end{array}$ \\
\hline Age & $<40$ years & $<40$ years \\
\hline Tumor size & $<$ or equal to $2 \mathrm{~cm}$ & $<$ or equal to $4 \mathrm{~cm}$ \\
\hline $\begin{array}{l}\text { Tumor-internal } \\
\text { os distance }\end{array}$ & $>1 \mathrm{~cm}$ & $<0.5 \mathrm{~cm}$ \\
\hline $\begin{array}{l}\text { Extrauterine } \\
\text { spread }\end{array}$ & Absent & Absent \\
\hline
\end{tabular}

Other findings include diffuse vaginal wall thickening/edema present up to 1 year postsurgery that slowly resolve without treatment, resolving vaginal wall hematomas and submucosal fluid collections. ${ }^{57}$ Posttrachelectomy complications include uterovaginal stenosis, infections/abscess, and lymphoceles.

\section{Adenoma Malignum}

It is a subtype of mucinous adenocarcinoma of cervix with very low prevalence. Watery discharge is the initial symptom, later menorrhagia may be present. It is difficult to diagnose as imaging appearance mimics benign multiple nabothian cysts or endocervical hyperplasia. On MRI, it appears as multicystic lesion seen as T2W hyperintense signal, extending from endocervical mucosa to deep cervical stroma with enhancing solid component. ${ }^{58}$ It is often associated with Peutz-Jeghers syndrome.

\section{Extension from Endometrial Carcinoma}

Endometrial carcinoma is the most common gynecologic cancer in industrialized countries. Stage-I endometrial carcinomas are tumors confined to endometrial cavity or invading inner half of myometrium. Involvement of the endocervical glands and mucosa without cervical stromal invasion is also considered stage I. On MRI, the endometrial tumor appears isointense relative to hypointense normal endometrium on T1W images, heterogeneous intermediate relative to hyperintense to normal endometrium and hyperintense to myometrium on T2W images. Endometrial tumors enhance early on DCE and show restricted diffusion as compared with normal endometrium. These tumors are hypoenhancing as compared with myometrial enhancement. Stage-II endometrial carcinoma represents cervical stromal invasion. Stage-II cancer is associated with a higher risk of lymphovasuclar invasion; hence, it is important to note cervical stromal invasion on $\mathrm{MRI}^{60}$ (-Fig. 30). In patients with bulky uterine masses, often biopsy and histology may not establish the origin of tumor cervical or endometrial; however, immunohistochemistry may provide the diagnosis. Bourgioti et al designed a 7-point MRI scoring system to determine the origin of uterine carcinoma (cervical vs. endometrial) in histologically indeterminate cases. These are tumor location (uterine body vs. cervix), perfusion pattern, that is, tumor hypervascularity on early arterial DCE MRI, rim enhancement, depth of myometrial invasion, cervical stromal invasion, intracavitary mass, and retained endometrial secretions. ${ }^{61}$

\section{Conclusion}

MRI is the imaging modality of choice for evaluating cervical pathologies, differentiating benign versus malignant lesions, accurately staging the malignancy, to evaluate response to treatment, detection of early tumor recurrence, and potential complications. Interpretation of posttreatment scan in patients with cervical cancer can be challenging because of expected changes in the pelvic organs. The radiologist must be familiar with these changes to avoid potential pitfalls. 


\section{Financial Support and Sponsorship \\ None.}

\section{Conflicts of Interest}

There are no conflicts of interest.

\section{References}

1 II: The anatomy of the uterine cervix and isthmus. Acta Radiol 1952;os-37(91,suppl):9-12

2 Klüner C, Hamm B, Normal imaging findings of the uterus. In: Hamm B, Forstner R, Beinder E, eds. MRI and CT of the Female Pelvis. Berlin, Germany: Springer; 2007 37-47

3 Ferenczy A, Anatomy and histology of the cervix. In: Blaustein A, ed. Pathology of the Female Genital Tract. New York, NY: Springer; 1977 102-3

4 Agrawal G. Part I: MR of the female pelvis. Available at: https:// www.appliedradiology.com/articles/part-i-mr-of-the-femalepelvis. Accessed July 22, 2021

5 Johnson W, Taylor MB, Carrington BM, Bonington SC, Swindell R. The value of hyoscine butylbromide in pelvic MRI. Clin Radiol 2007;62(11):1087-1093

6 Camis CC, Brenna SMF, Lombardelli KVP, Maria Célia R. Djahjah: magnetic resonance imaging in the staging of cervical cancer. Radiol Bras 2007;40:207-215

7 Okamoto Y, Tanaka YO, Nishida M, Tsunoda H, Yoshikawa H, Itai Y. MR imaging of the uterine cervix: imaging-pathologic correlation. Radiographics 2003;23(2):425-445, quiz 534-535

8 Keriakos NN, Darwish E. Diffusion-weighted imaging in suspicious uterine tumors; how efficient is it? Egypt J Radiol Nucl Med 2018;49:838-845

9 Bin Park S, Lee JH, Lee YH, Song MJ, Choi HJ. Multilocular cystic lesions in the uterine cervix: broad spectrum of imaging features and pathologic correlation. AJR Am J Roentgenol 2010;195(2):517-523

10 Kuang F, Yan Z, Li H, Feng H. Diagnostic accuracy of diffusion-weighted MRI for differentiation of cervical cancer and benign cervical lesions at 3.0T: Comparison with routine MRI and dynamic contrast-enhanced MRI. J Magn Reson Imaging 2015;42(4):1094-1099

11 Jones MA, Young RH. Endocervical type A (noncystic) tunnel clusters with cytologic atypia. A report of 14 cases. Am J Surg Pathol 1996;20(11):1312-1318

12 Balleyguier C, Sala E, Da Cunha T, et al. Staging of uterine cervical cancer with MRI: guidelines of the European Society of Urogenital Radiology. Eur Radiol 2011;21(5):1102-1110

13 Behr SC, Courtier JL, Qayyum A. Imaging of müllerian duct anomalies. Radiographics 2012;32(6):E233-E250

14 Mueller GC, Hussain HK, Smith YR, et al. Müllerian duct anomalies: comparison of MRI diagnosis and clinical diagnosis. AJR Am J Roentgenol 2007;189(6):1294-1302

15 Troiano RN, McCarthy SM. Mullerian duct anomalies: imaging and clinical issues. Radiology 2004;233(1):19-34

16 Robbins JB, Parry JP, Guite KM, et al. MRI of pregnancy-related issues: müllerian duct anomalies. AJR Am J Roentgenol 2012;198(2):302-310

17 Elamparidhi P, Kumar RR, Sivaranjinie S, Sibhithran R. Mullerian agenesis associated with Turner's syndrome. J Clin Diagn Res 2017; 11(2):TD01-TD02

18 Carrington BM, Hricak H, Nuruddin RN. Secaf E, Laros RK Jr., Hill EC. Müllerian duct anomalies: MR imaging evaluation. Radiology 1990;176(3):715-720

19 Segal GH, Hart WR. Cystic endocervical tunnel clusters. A clinicopathologic study of 29 cases of so-called adenomatous hyperplasia. Am J Surg Pathol 1990;14(10):895-903

20 Young RH, Clement PB. Pseudoneoplastic glandular lesions of the uterine cervix. Semin Diagn Pathol 1991;8(4):234-249
21 Sugiyama K, Takehara Y. MR findings of pseudoneoplastic lesions in the uterine cervix mimicking adenoma malignum. Br J Radiol 2007;80(959):878-883

22 Takatsu A, Shiozawa T, Miyamoto T, et al. Preoperative differential diagnosis of minimal deviation adenocarcinoma and lobular endocervical glandular hyperplasia of the uterine cervix: a multicenter study of clinicopathology and magnetic resonance imaging findings. Int J Gynecol Cancer 2011;21(7):1287-1296

23 Tiltman AJ. Leiomyomas of the uterine cervix: a study of frequency. Int J Gynecol Pathol 1998;17(3):231-234

24 Ueda H, Togashi K, Konishi I, et al. Unusual appearances of uterine leiomyomas: MR imaging findings and their histopathologic backgrounds. Radiographics 1999;19(Spec No): S131-S145

25 Stamatellos I, Stamatopoulos P, Bontis J. The role of hysteroscopy in the current management of the cervical polyps. Arch Gynecol Obstet 2007;276(4):299-303

26 Golan A, Ber A, Wolman I, David MP. Cervical polyp: evaluation of current treatment. Gynecol Obstet Invest 1994;37(1):56-58

27 Coutinho A Jr., Bittencourt LK, Pires CE, et al. MR imaging in deep pelvic endometriosis: a pictorial essay. Radiographics 2011;31(2):549-567

28 Tamai K, Togashi K, Ito T, Morisawa N, Fujiwara T, Koyama T. MR imaging findings of adenomyosis: correlation with histopathologic features and diagnostic pitfalls. Radiographics 2005;25(1):21-40

29 Novellas S, Chassang M, Delotte J, et al. MRI characteristics of the uterine junctional zone: from normal to the diagnosis of adenomyosis. AJR Am J Roentgenol 2011;196(5):1206-1213

30 Ascher-Walsh CJ, Tu JL, Du Y, Blanco JS. Location of adenomyosis in total hysterectomy specimens. J Am Assoc Gynecol Laparosc 2003;10(3):360-362

31 Park J, Kim T, Lee H, Lee W, Chung S, Park S. Cervical endometriosis in a post-menopausal woman: a case report. J Korean Soc Menopause 2011;17:174-177

32 Phadnis SV, Doshi JS, Ogunnaike O, Coady A, Padwick M, Sanusi FA. Cervical endometriosis: a diagnostic and management dilemma. Arch Gynecol Obstet 2005;272(4):289-293

33 Ata B, Ates U, Usta T, Attar E. Cervical endometriosis, a case presenting with intractable spotting. MedGenMed 2005;7(2):64

34 Wang S, Li XC, Lang JH. Cervical endometriosis: clinical character and management experience in a 27-year span. Am J Obstet Gynecol 2011;205(5):452.e1-452.e5

35 Szyfelbein WM, Baker PM, Bell DA. Superficial endometriosis of the cervix: A source of abnormal glandular cells on cervicovaginal smears. Diagn Cytopathol 2004;30(2):88-91

36 Bennett GL, Slywotzky CM, Cantera M, Hecht EM. Unusual manifestations and complications of endometriosisspectrum of imaging findings: pictorial review. AJR Am J Roentgenol 2010;194(6, suppl):WS34-WS46

37 Steinkeler JA, Woodfield CA, Lazarus E, Hillstrom MM. Female infertility: a systematic approach to radiologic imaging and diagnosis. Radiographics 2009;29(5):1353-1370

38 Guven S, Ilıca T, Yılmaz A, Alanbay I. A case of asymptomatic postmenopausal hematometra mimicking endometrial carcinoma. Gynecol Obstet Reprod Med 2007;13:67-69 ISSN $1300-4751$

39 Bray F, Ferlay J, Soerjomataram I, Siegel RL, Torre LA, Jemal A. Global cancer statistics 2018: GLOBOCAN estimates of incidence and mortality worldwide for 36 cancers in 185 countries. CA Cancer J Clin 2018;68(6):394-424

40 Patel S, Liyanage SH, Sahdev A, Rockall AG, Reznek RH. Imaging of endometrial and cervical cancer. Insights Imaging 2010;1(5-6):309-328

41 Bhatla N, Berek JS, Cuello Fredes M, et al. Revised FIGO staging for carcinoma of the cervix uteri. Int J Gynaecol Obstet 2019;145(1):129-135 
42 Zand KR, Reinhold C, Abe H, Maheshwari S, Mohamed A, Upegui D. Magnetic resonance imaging of the cervix. Cancer Imaging 2007;7:69-76

43 Rockall AG, Ghosh S, Alexander-Sefre F, et al. Can MRI rule out bladder and rectal invasion in cervical cancer to help select patients for limited EUA? Gynecol Oncol 2006;101(2):244-249

44 Delgado G, Bundy BN, Fowler WC Jr, et al. A prospective surgical pathological study of stage I squamous carcinoma of the cervix: a Gynecologic Oncology Group Study. Gynecol Oncol 1989;35(3):314-320

45 Inoue T. Prognostic significance of the depth of invasion relating to nodal metastases, parametrial extension, and cell types. A study of 628 cases with Stage IB, IIA, and IIB cervical carcinoma. Cancer 1984;54(12):3035-3042

46 Trattner M, Graf AH, Lax S, et al. Prognostic factors in surgically treated stage ib-iib cervical carcinomas with special emphasis on the importance of tumor volume. Gynecol Oncol 2001;82(1):11-16

47 Yang WT, Lam WW, Yu MY, Cheung TH, Metreweli C. Comparison of dynamic helical CT and dynamic MR imaging in the evaluation of pelvic lymph nodes in cervical carcinoma. AJR Am J Roentgenol 2000;175(3):759-766

48 Atri M, Zhang Z, Dehdashti F, et al. Utility of PET-CT to evaluate retroperitoneal lymph node metastasis in advanced cervical cancer: Results of ACRIN6671/GOG0233 trial. Gynecol Oncol 2016;142(3):413-419

49 Choi HJ, Ju W, Myung SK, Kim Y. Diagnostic performance of computer tomography, magnetic resonance imaging, and positron emission tomography or positron emission tomography/computer tomography for detection of metastatic lymph nodes in patients with cervical cancer: meta-analysis. Cancer Sci 2010;101(6):1471-1479

50 National Comprehensive Cancer Network. Cervical cancer 2018. Available at: https://www2.tri-kobe.org/nccn/ guideline/archive/gynecological2018/english/cervical.pdf.

51 Bhatla N, Aoki D, Sharma DN, Sankaranarayanan R. Cancer of the cervix uteri. Int J Gynaecol Obstet 2018;143(suppl 2):22-36
52 Chai Y, Wang T, Wang J, et al. Radical hysterectomy with adjuvant radiotherapy versus radical radiotherapy for FIGO stage IIB cervical cancer. BMC Cancer 2014;14:63

53 Marin F, Plesca M, Bordea CI, Moga MA, Blidaru A. Types of radical hysterectomies : from Thoma Ionescu and Wertheim to present day. J Med Life 2014;7(2):172-176

54 Ramirez PT, Pareja R, Rendón GJ, Millan C, Frumovitz M, Schmeler KM. Management of low-risk early-stage cervical cancer: should conization, simple trachelectomy, or simple hysterectomy replace radical surgery as the new standard of care? Gynecol Oncol 2014;132(1):254-259

55 Bourgioti C, Chatoupis K, Moulopoulos LA. Current imaging strategies for the evaluation of uterine cervical cancer. World J Radiol 2016;8(4):342-354

56 Papadopoulou I, Stewart V, Barwick TD, et al. Post-radiation therapy imaging appearances in cervical carcinoma. Radiographics 2016;36(2):538-553

57 Mahajan M, Kuber R, Chaudhari K, Chaudhari P, Ghadage P, Naik R. MR imaging of carcinoma cervix. Indian J Radiol Imaging 2013;23(3):247-252

58 Ki EY, Byun SW, Park JS, Lee SJ, Hur SY. Adenoma malignum of the uterine cervix: report of four cases. World J Surg Oncol 2013;11:168

59 Peppercorn PD, Jeyarajah AR, Woolas R, et al. Role of MR imaging in the selection of patients with early cervical carcinoma for fertility-preserving surgery: initial experience. Radiology 1999;212(2):395-399

60 Freeman SJ, Aly AM, Kataoka MY, Addley HC, Reinhold C, Sala E. The revised FIGO staging system for uterine malignancies: implications for MR imaging. Radiographics 2012;32(6):1805-1827

61 Bourgioti C, Chatoupis K, Panourgias E, et al. Endometrial vs. cervical cancer: development and pilot testing of a magnetic resonance imaging (MRI) scoring system for predicting tumor origin of uterine carcinomas of indeterminate histology. Abdom Imaging 2015;40(7):2529-2540 